\section{CHECK UPS FOR WINTER GAMES ATHLETES}

The International Olympic Committee (IOC) screened a record number of athletes for oral cancer during the 2010 winter games in Vancouver, Canada.

The UK's leading oral health campaigners have backed the decision, with dentists screening $20 \%$ of all athletes - a 100\% rise from the last Winter Olympics, during course of the games.

Around 800 athletes sat in the dentist's chair during the competition, with over 70 dentists and their assistants on hand to not only to fix teeth and mouths, but to also practice preventative dentistry.

The British Dental Health Foundation has supported the increased oral screening campaign that also included education for athletes on the importance of applying sun-cream to help prevent mouth cancers. Alpine athletes are particularly in danger of developing skin and lip cancers due to prolonged exposure to harmful ultraviolet radiation while training and

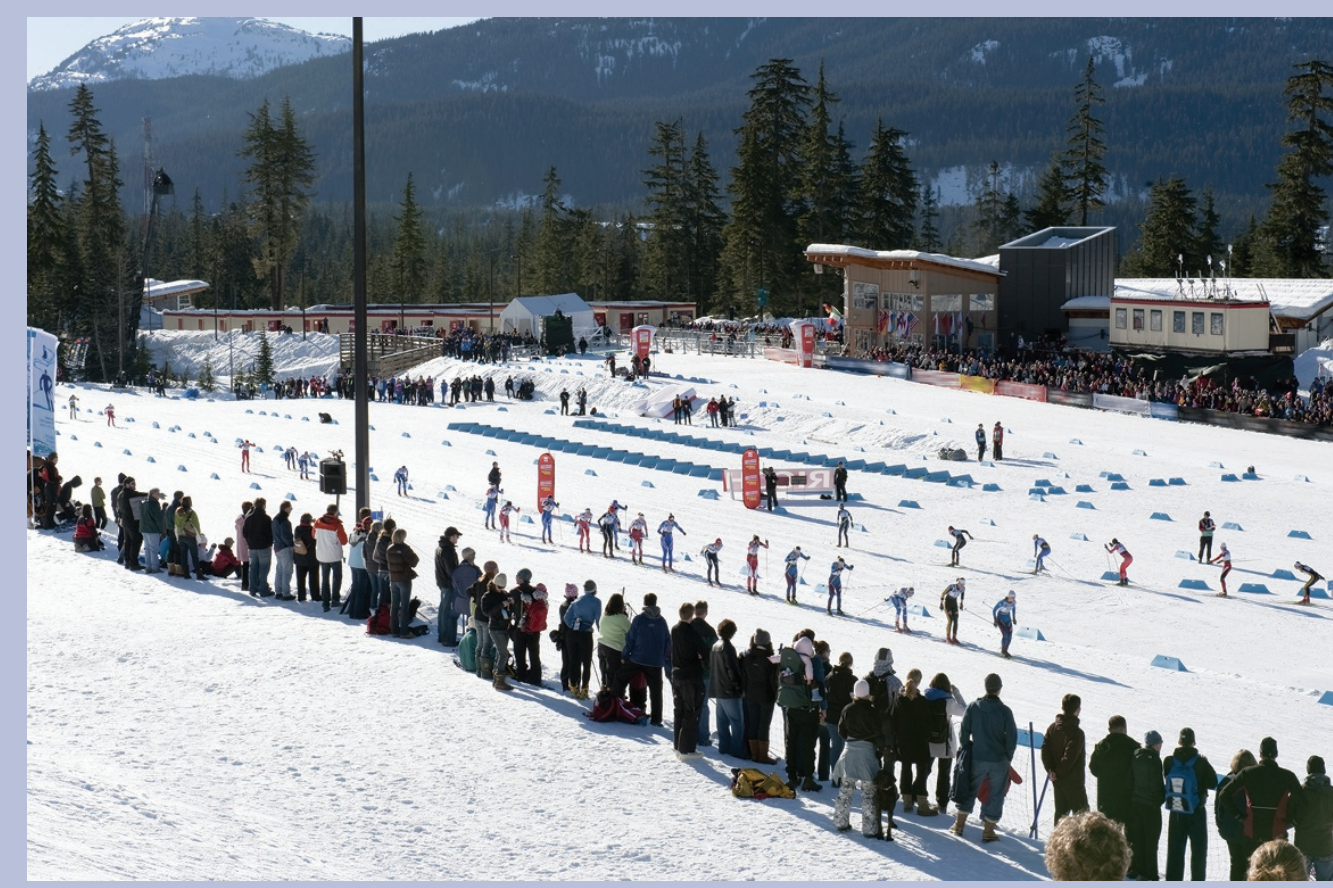

Whistler Olympic Park

competing at high altitudes. The damaging radiation largely occurs when the sun reflects off the surface of the ice and snow.

Chief Executive of the British Dental Health Foundation, Dr Nigel Carter was pleased to see the Olympic Committee recognise the importance of spreading the awareness of mouth cancer and said, 'It is high time this hidden problem was placed in the spotlight. It is good to see positive action taking place by raising knowledge of the risks and ability to spot this disease.'

\title{
ROYAL ARMY DENTAL CORPS DIRECTOR TAKES REINS
}

Brigadier Nick Young L/RADC has recently been appointed Director of the Army Dental Service. Brigadier Young qualified in dentistry from Birmingham University in 1978 and started his dental career as a house officer in oral and maxillofacial surgery at Kidderminster and Bromsgrove District General Hospitals.

After time in NHS dental practice in Shropshire he joined the Royal Army Dental Corps in 1982. He served in numerous dental officer appointments both in the UK and Germany and has held various posts worldwide.

His new role as Director, Army Dental Services is in addition to his present appointment, since July 2009, as Director for British Forces Germany Health Service. In this strategic medical role he is responsible for delivery of all primary and secondary medical care to HM Forces and their dependents in Europe and he is presently based not far from Düsseldorf.

Brigadier Young sees his fundamental role as Director, Army Dental Service to be to deliver and maintain military personnel dentally fit for current operations, especially in Afghanistan, set against the stringent financial restraints omnipresent for all public sector organisations.

His vision is to promote within military dentistry an environment where all personnel, irrespective of rank or position, can maximise their opportunity develop professionally as members of the dental team. He will also continue to enrich the Defence Dental Services' vocational training scheme.

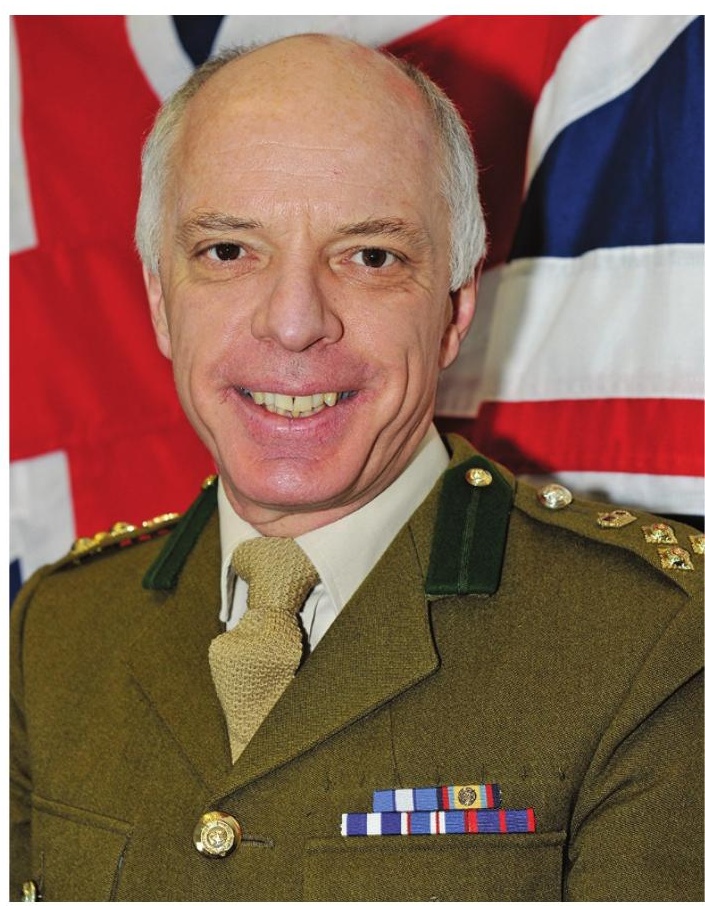

